\title{
Efficacy of the Ipratropium Bromide in Moderate and Severe Asthma Attack in Children
}

\author{
Mehmet Özdemir ${ }^{1}$, (1) Haluk Çokuğraş²
}

${ }^{1}$ Department of Pediatrics, Division of Pediatric Allergy, Medeniyet University Faculty of Medicine, Istanbul, Turkey

${ }^{2}$ Department of Pediatrics, Division of Immunology-Allergy and Infectious Diseases, Istanbul University, Cerrahpasa Faculty of Medicine, Istanbul, Turkey

\begin{abstract}
Introduction: Standard therapy for acute asthma attack includes beta 2 agonists, $\mathrm{O}_{2}$ and systemic corticosteroids. Although there is a widespread usage of this therapy protocol in recent years, as some of the children still need hospitalization because of incomplete responses, adjunctive therapy measures should be considered. We planned this study protocol to assess the effects of ipratropium bromide (IB) for moderate and severe childhood asthma attacks.

Methods: All of the consecutive 50 children admitted to the Pediatric Emergency Service of İstanbul University Cerrahpaşa Medicine Faculty were included in our study. All patients received short duration $\beta 2$-adrenergic agonists and methylprednisolone consistent with current practice guidelines; then, they were randomized into two groups. While the first group received IB $(250 \mu \mathrm{g} /$ dosage $)$ three times with 20 minutes of intervals, the second group received serum physiologic. Before each therapy regimen and at the $72^{\text {nd }}$ hour, clinical asthma scores (CAS) and peak expiratory flow rates (PEF) of the patients were screened and their hospitalization status was recorded.

Results: There was not any significant difference in the hospitalization status of the two groups, which included patients aged three to 18 years. Clinical asthma scores and PEFR of the first and second group of patients had a statistically significant difference beginning from the $40^{\text {th }}$ minute.

Discussion and Conclusion: In our study, we reported that IB added to the standard therapy regimen of moderate and severe childhood asthma attacks was efficient and did not have any adverse effect.

Keywords: Acute asthma attacks; childhood; ipratropium bromide.
\end{abstract}

A sthma is a chronic inflammatory disease presenting with acute asthma attacks. National diagnoses and management reports recommend oxygen, short-acting $\beta 2$-adrenergic agonists and systemic corticosteroids for the management of acute asthma attack ${ }^{[1,2]}$. As some patients do not respond completely to the optimal therapy regimen applied, adjunctive therapy measures should be considered. Ipratropium bromide (IB) is a quaternary anticholinergic and when it is used in conjunction with $\beta 2-$ adrenergic agonists, they have additive effects in improving the pulmonary function ${ }^{[3-6]}$. The bronchodilator effect of ipratropium bromide starts at 30-120 minutes, lasts 4-8 hours and has a half-life of 3.2 hours ${ }^{[6,7]}$.

In our study, the efficacy and adverse effects of (if there is)

Correspondence (İletişim): Mehmet Özdemir, M.D. Istanbul Medeniyet Universitesi, Goztepe Egitim ve Arastirma Hastanesi, Cocuk Sagligi ve Hastaliklari Anabilim Dali, Alerji Bilim Dali, Istanbul, Turkey

Phone (Telefon): +90 5055890983 E-mail (E-posta): mehmetozdemir@yahoo.com

Submitted Date (Başvuru Tarihi): 05.12.2018 Accepted Date (Kabul Tarihi): 02.01.2019

Copyright 2020 Haydarpaşa Numune Medical Journal

OPEN ACCESS This is an open access article under the CC BY-NC license (http://creativecommons.org/licenses/by-nc/4.0/) 
nebulised IB, added to the $\beta 2$-agonist therapy regimen was evaluated by observing the symptom scores three times with 20 minutes of intervals and observing pulmonary function tests (PFT) of childhood moderate and severe asthma attacks.

\section{Materials and Methods}

Children admitted to the Pediatric Emergency Service of İstanbul University Cerrahpaşa Medicine Faculty with moderate and severe childhood asthma attacks were included in our study this stufy approved by our hospitals instutional boards. Patients aged three to 12 years and with clinical asthma scores $(\mathrm{CAS})^{[8]}$ and with PEFR $<70 \%$ participated with the consent of their families. Patients who received corticosteroids during the last three days and bronchodilator drugs during the last six hours, who had prior intensive care unit history and who had diseases like glaucoma and cardiac disorders, and who had known hypersensitivities to the drug were excluded from the study. The severity of the asthma attacks of our cases was classified according to the PEFR or CAS (Table 1). The patients were randomized into two groups; and PEFR, clinical asthma scores, heart rate, minute respiration rate, $\mathrm{O}_{2}$ saturation and blood pressure of each patient was recorded. Each patient participated in this study received nebulised salbutamol dosages (if the patient's weight was $<30 \mathrm{~kg}, 2.5 \mathrm{mg}$ salbutamol; if the patient's weight was $>30 \mathrm{~kg}, 5 \mathrm{mg}$ salbutamol) three times with 20 minutes of intervals in between and one dosage of $2 \mathrm{mg} / \mathrm{kg}$ (max. $60 \mathrm{mg}$ ) intravenous methylprednisolone. First group of patients received $250 \mu \mathrm{g} /$ dosage of nebulised ipratropium bromide (Boehringer Ingelheim) three times with 20 minutes of intervals, and the second group of patients received $2 \mathrm{ml}$ nebulised serum physiologic three times with 20 minutes of intervals (Fig. 1). $\mathrm{O}_{2}$ therapy was with pulse oxymeter and when $\mathrm{O}_{2}$ saturation ( $\mathrm{BCl}$ International Waukesha, Wisconsin USA) was $\leq 94 \%$, it was 6 liters/ minute.

Initial parameters were assessed at the beginning of this study, and then measured again at the $20^{\text {th }}, 40^{\text {th }}$ and $60^{\text {th }}$

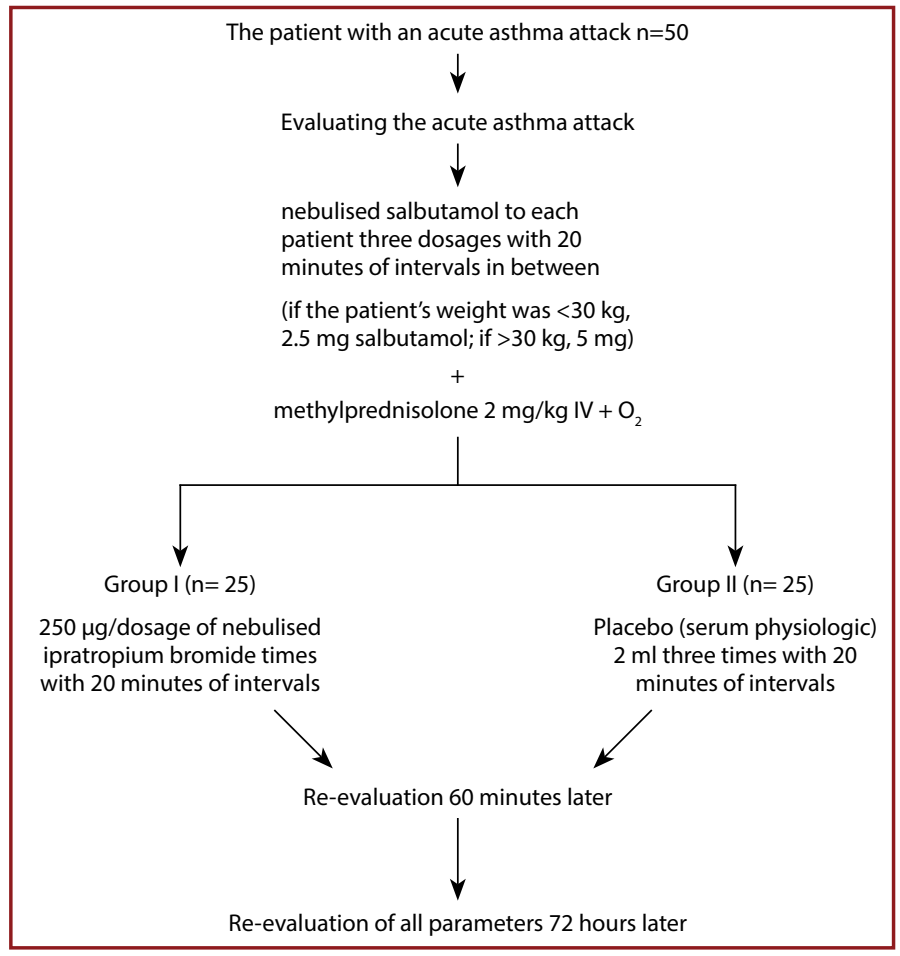

Figure 1. Study plan.

minutes after each therapy regimen. Patients were followed for adverse effects (defined by the patient or observed by the primary physician). The need for adjunctive therapy measures after the initial one hour of therapy and the need for hospitalization should be assessed by the physician observing the patient clinically. The patients were hospitalized when there were clinical and PEFR changes, or when the $\mathrm{O}_{2}$ saturation of the room-air was $<94 \%$. Time for each nebulisation therapy, hospitalization status of the patients and discharge day from the hospital was recorded with details. Out-patients were admitted to controls 72 hours later to re-evaluate all of the tests initially measured. PEFR was measured with SensorMedics Vmax Series 20C spirometers (SensorMedics Corporation Yorba Linda California). The highest level measured at the end of 3 measure performed is defined as a PEFR.

Table 1. Evaluation of the clinical asthma scores

\begin{tabular}{|c|c|c|c|}
\hline Severity & Wheeze score & Dyspnea score & Accessory muscle score \\
\hline 1 & End-expiratory wheeze & Normal activity and speech, minimal dyspnea & Interkostal retractions \\
\hline 3 & $\begin{array}{l}\text { Wheeze audible without a } \\
\text { stethoscope }\end{array}$ & $\begin{array}{l}\text { Concentrates on breathing; } \leq 5 \text {-word sentences; } \\
\text { severe dyspnea }\end{array}$ & Nasal flaring \\
\hline
\end{tabular}


Patients in the therapy group and control group were compared for the beginning time of the disease, the number of attacks experienced during the last year, hospitalization rates because of attacks experienced during the last year, and for ECP levels, with the Mann-Whitney U test. KruskalWallis test was used to compare the PEFR and CAS before and after the two therapy regimens. The difference was statistically significant when the " $p$ "-value was $<0.05$, and data were evaluated with "SPSS" statistical program.

\section{Results}

A total of 50 children, 30 male (60\%) and 20 female (40\%), admitted to the Pediatric Emergency Service of İstanbul University Cerrahpaşa Medicine Faculty with acute asthma attack participated in our study and all of the patients completed this study.

While of 25 cases ( 15 male, 10 female) in the first group had a "median age of $6.61 \pm 2.21$ years; 25 cases (15 male, 10 female) in the second group had a "median age of $6.68 \pm 2.92$ years and there was not any statistically significant difference in the demographical characteristics of these groups (Table 2).

It was found that while nine patients had a severe asthma attack (5 patients in the first group; 4 patients in the second group), 41 patients had a moderate asthma attack (20 patients in the first group; and 21 patients in the second group) (Table 3).

One patient (4\%) in the first group and three patients (12\%) in the second group were hospitalized. Although the number of patients hospitalized in the combined therapy group was lower than the other group, there was not a statistically significant difference $(p>0.05)$ (Table 3$)$. None of the discharged patients were admitted to the Emergency Service within 72 hours.

There was not any adverse effect defined by the physician or by the patient in both groups.

PEFR was evaluated in 19 children (10 patients in group I; and 9 patients in group II) who are over seven years of age. PEFR was significantly improved at the 60th minute in both groups $(p<0.001)$, but when the two groups were compared, there was a statistically significant difference as soon as the second therapy had been started $\left(40^{\text {th }}\right.$ minute), and this difference continued at the $72^{\text {nd }}$ hour $(p<0.05)$ (Table 4).

At the end of the first hour, CAS of both groups had decreased significantly $(p<0.001)$ (Table 4$)$. However, when the two groups were compared, like improvement in PEFR, there was a statistically significant difference after the second therapy had been completed ( $40^{\text {th }}$ minute), and this difference continued at the $72^{\text {nd }}$ hour $(p<0.05)$ (Table 4$)$.

\section{Discussion}

Acute severe asthma attacks in children are life-threatening emergencies. According to pediatric guidelines, three dosages of $\beta 2$-agonist (with 20 minutes of intervals in between), systemic corticosteroids and $\mathrm{O}_{2}$ therapy is rec-

Table 2. Baseline characteristics of the study groups: Clinical demographics

\begin{tabular}{lcc}
\hline & Group I (n=25) & Group II (n=25) \\
\hline Age (years) & $6.61 \pm 2.21$ & $6.86 \pm 2.92$ \\
M/F & $15 / 10$ & $15 / 10$ \\
The beginning age for the disease & $2 \pm 2.14$ & $2.14 \pm 1.33$ \\
The number of admittances to the Emergency Service & $2.96 \pm 1.38$ & $3.12 \pm 2.99$ \\
with an acute asthma attack during the last year & & 0.93 \\
The number of hospitalizations during the last year & 0 & 0 \\
The number of allergens positive with prick test & $2.82 \pm 1.42$ & $3,30 \pm 1,46$ \\
Atopy (patient or family history) & $48 \%$ & $56 \%$ \\
Receiving prophylactic drug therapy & $72 \%$ & $84 \%$ \\
Respiratory rate (breaths/min) & $48.08 \pm 8.82$ & $48.44 \pm 6.78$ \\
Heart rate (beats/min) & $125.96 \pm 16.55$ & $124.80 \pm 14.45$ \\
Initial O saturation \% (room air) & $94.2 \pm 1.29$ & $94.78 \pm 1.42$ \\
Accessory muscle contractions & $1.92 \pm 0,4$ & $2 \pm 0.41$ \\
Wheeze score & $2.2 \pm 0.41$ & 0.15 \\
Dyspnea score & $1.68 \pm 0.47$ & 0.57 \\
Clinical asthma score & $5.80 \pm 1$ & 0.31 \\
ECP (IU/ml) & $25.27 \pm 20.62$ & 0.87 \\
PEFR (\% predicted) & $55.30 \pm 6.93$ & 0.79 \\
\hline
\end{tabular}


Table 3. The number and severity of the attacks of our patients

\begin{tabular}{lccc}
\hline & Group I & Group II & p \\
\hline $\begin{array}{l}\text { The severity of the attack } \\
\text { Medium 41 (82\%) }\end{array}$ & Medium 20 (80\%) & Medium 21 (84\%) & \\
Severe 9 (18\%) & Severe 5 (20\%) & Severe 4 (16\%) & \\
the number of patients & 1 & 3 & 0.09 \\
hospitalized & & & \\
\hline
\end{tabular}

Table 4. The median values for the PEFR and CAS of each group

\begin{tabular}{ccccc}
\hline & Time & I. Group & II. Group & p \\
\hline PEFR & 0. $\min$ & $55.30 \pm 6.93$ & $53.78 \pm 9.95$ & 0.7 \\
& 20. $\min$ & $71.10 \pm 9.55$ & $63.44 \pm 9.34$ & 0.09 \\
& 40. $\min$ & $77.20 \pm 5.9$ & $69.89 \pm 7.27$ & 0.02 \\
& 60. $\min$ & $88.60 \pm 6.35$ & $78.33 \pm 9.62$ & 0.01 \\
& 72. hours & $99.9 \pm 15.86$ & $81.44 \pm 10.69$ & 0.009 \\
CAS & 0. $\min$ & $5.80 \pm 1$ & $5.76 \pm 1.01$ & 0.88 \\
& 20. $\min$ & $3.76 \pm 0.87$ & $4.04 \pm 1.24$ & 0.08 \\
& 40. $\min$ & $2.04 \pm 0.93$ & $2.76 \pm 1.56$ & 0.02 \\
& 60. $\min$ & $0.48 \pm 0.77$ & $1.44 \pm 1.66$ & 0.01 \\
& 72. hours & $0.04 \pm 0.2$ & $0.32 \pm 04$ & 0.009 \\
\hline
\end{tabular}

ommended for acute asthma attacks ${ }^{[1,9,10]}$. Despite this standard therapy, it is reported that some patients do not recover completely. Thus, usage of adjunctive therapy measures is frequently discussed. The efficacy and safety of the IB for adult patients and its synergistic effects with $\beta 2$ agonists have been reported in many studies ${ }^{[11-16]}$. Studies on children have reported that FEV1 have improved considerably in children on combined therapy regimen with $\beta 2$-agonist + ipratropium bromide when compared with children on single-drug regimen with $\beta 2$-agonists ${ }^{[8,17,18]}$. In contrast, there are also other studies where the superiority of combined therapy cannot be proved ${ }^{[19-21]}$.

In our study, group I receiving three dosages of $\beta 2$-agonist (with 20 minutes of intervals) + IB and group II receiving three dosages of $\beta 2$-agonist (with 20 minutes of intervals) + serum physiologic were compared and CAS and PEFR improved in a statistically significant manner in the combined therapy group. When combined therapy is received as six dosages with 20 minutes of intervals, it is proved to be more useful than the single therapy regimen ${ }^{[22]}$, and again, FEV1 has improved significantly in children receiving six dosages of $\beta 2$-agonist (with 20 minutes of intervals) + IB (with 20 minutes of intervals) ${ }^{[23]}$. In our study, combined therapy applied by decreasing dosage numbers and dosage intervals was efficient in moderate and severe asthma attacks and improved CAS and pulmonary function tests. Despite optimum management, some of the children experiencing acute asthma attacks are hospitalized be- cause of continuing airway resistance. However, when IB is combined with the standard $\beta 2$-agonist therapy, hospitalization rates have decreased in a statistically significant manner ${ }^{[14,24-27]}$. In our study, one patient in group I, and three patients in group II were hospitalized, and although there were few patients hospitalized on the combined therapy group, there was not any statistically significant difference between them ( $p>0.09$ ).

In our study, besides clinical observation, pulmonary function tests were used to assess the efficacy of the therapy objectively. PEFR and CAS of the cases receiving combined therapy improved in a significant manner when compared with the cases receiving only $\beta 2$-agonists and both the improvement in PEFR and in CAS had started at the fourteenth minute.

As the systemic absorption of the small intestine is very weak, its adverse effects should be low. There was not any side-effect in our study. The results of our study should not be generalized for mild childhood asthma, as mild asthma attacks generally respond to $\beta 2$-agonist therapy. Thus, nebulised IB received as three dosages (with 20 minutes of intervals) combined to the standard therapy ( $\beta 2$ agonist+systemic corticosteroids $+\mathrm{O}_{2}$ ) improves both the symptom scores and pulmonary function tests of childhood asthma beginning from the fourteenth minute and do not have any adverse effects.

\section{Peer-review: Externally peer-reviewed.}

Authorship Contributions: Concept: M.O.; Design: M.O., HC.; Data Collection or Processing: M.O.; Analysis or Interpretation: M.O., H.C.; Literature Search: M.O.; Writing: M.O., H.C.

Conflict of Interest: None declared.

Financial Disclosure: The authors declared that this study received no financial support.

\section{References}

1. National asthma education and prevention program expert panel report II: Guidelines for the diagnosis and management of asthma. National Institutes of Health, National Heart, Lung and Blood Institute, Publ. No:1997;40-51.

2. Indinnimeo L, Chiappini E, Miraglia Del Giudice M; Italian Panel for the management of acute asthma attack in children Roberto Bernardini. Guideline on management of the acute asthma attack in children by Italian Society of Pediatrics. Ital J Pediatr 2018;44:46. [CrossRef]

3. Inayat N, Shah RH, Rahu QA, Sahito R. Nebulized salbutamol with \& without ipratropium bromide in the treatment of acute severe asthma. Pak J Chest Med 2016;22:102-6.

4. Summers QA, Tarala RA. Nebulized ipratropium in the treatment of acute asthma. Chest 1990;97:425-9. [CrossRef] 
5. Aaron SD. The use of ipratropium bromide for the management of acute asthma exacerbation in adults and children: $a$ systematic review. J Asthma 2001;38:521-30. [CrossRef]

6. Zorc JJ, Pusic MV, Ogborn CJ, Lebet R, Duggan AK. Ipratropium bromide added to asthma treatment in the pediatric emergency department. Pediatrics 1999;103:748-52. [CrossRef]

7. Gross NJ. Ipratropium bromide. N Engl J Med 1988;319:48694. [CrossRef]

8. DeStefano G, Bonetti S, Bonizzato C, Valletta EA, Piacentini $\mathrm{GL}$, Boner AL. Additive effect of albuterol and ipratropium bromide in the treatment of bronchospasm in children. Ann Allergy 1990;65:260-2.

9. Peters J, Melo J. Asthma exacerbations: Key point from the NIH guidelines. J Respir Dis 1998;19;346-63.

10. Warner JO, Naspitz CK. Third International Pediatric Consensus statement on the management of childhood asthma. International Pediatric Asthma Consensus Group. Pediatr Pulmonol 1998;25:1-17. [CrossRef]

11. Iramain R, López-Herce J, Coronel J, Spitters C, Guggiari J, Bogado N. Inhaled salbutamol plus ipratropium in moderate and severe asthma crises in children. J Asthma 2011;48:298-303.

12. Rebuck AS, Chapman KR, Abboud R, Pare PD, Kreisman H, Wolkove $\mathrm{N}$, et al. Nebulized anticholinergic and sympathomimetic treatment of asthma and chronic obstructive airways disease in the emergency room. Am J Med 1987;82:5964. [CrossRef]

13. Qureshi F, Zaritsky A, Lakkis H. Efficacy of nebulized ipratropium in severely asthmatic children. Ann Emerg Med 1997;29:205-11. [CrossRef]

14. Louw SJ, Goldin JG, Isaacs S. Relative efficacy of nebulised ipratropium bromide and fenoterol in acute severe asthma. $\mathrm{S}$ Afr Med J 1990;77:24-6.

15. Chakraborti A, Lodha R, Pandey RM, Kabra SK. Randomized controlled trial of ipratropium bromide and salbutamol versus salbutamol alone in children with acute exacerbation of asthma. Indian J Pediatr 2006;73:979-83. [CrossRef]

16. Sharma A, Madaan A. Nebulized salbutamol vs salbutamol and ipratropium combination in asthma. Indian J Pediatr 2004;71:121-4. [CrossRef]
17. O'Driscoll BR, Taylor RJ, Horsley MG, Chambers DK, Bernstein A. Nebulised salbutamol with and without ipratropium bromide in acute airflow obstruction. Lancet 1989;1:1418-20.

18. Schuh S, Johnson DW, Callahan S, Canny G, Levison H. Efficacy of frequent nebulized ipratropium bromide added to frequent high-dose albuterol therapy in severe childhood asthma. J Pediatr 1995;126:639-45. [CrossRef]

19. Ducharme FM, Davis GM. Randomized controlled trial of ipratropium bromide and frequent low doses of salbutamol in the management of mild and moderate acute pediatric asthma. J Pediatr 1998;133:479-85. [CrossRef]

20. Cook JJ, Fergusson DM, Dawson KP. Ipratropium and fenoterol in the treatment of acute asthma. Pharmatherapeutica 1985;4:383-6.

21. Jiang WH, Deng L, Wen HH, Yu JL, Zeng Q. Effects of salbutamo and ipraopium bromide inhalation on pulmonary function in young children with asthmatoid bronchitis. Zhongguo Dang Dai Er Ke Za Zhi 2006;8:295-7.

22. Beck R, Robertson C, Galdès-Sebaldt M, Levison H. Combined salbutamol and ipratropium bromide by inhalation in the treatment of severe acute asthma. J Pediatr 1985;107:605-8.

23. Reismann J, Canny G, Levison $\mathrm{H}$. The role of anticholinergic drugs in paediatric airways disease. In: Gross N, editor. Anticholinergic therapy in obstructive airways disease. London: Franklin scientific Publications; 1993:169-70.

24. Qureshi F, Pestian J, Davis P, Zaritsky A. Effect of nebulized ipratropium on the hospitalization rates of children with asthma. N Engl J Med 1998;339:1030-5. [CrossRef]

25. Rodrigo G, Rodrigo C, Burschtin O. A meta-analysis of the effects of ipratropium bromide in adults with acute asthma. Am J Med 1999;107:363-70. [CrossRef]

26. Delacourt C, de Blic J, Lebourgeois M, Scheinmann P. Value of ipratropium bromide in asthma crisis in children. Arch Pediatr 1994;1:87-92. [Article in French]

27. Lanes SF, Garrett JE, Wentworth CE 3rd, Fitzgerald JM, Karpel JP. The effect of adding ipratropium bromide to salbutamol in the treatment of acute asthma: a pooled analysis of three trials. Chest 1998;114:365-72. [CrossRef] 